\title{
Water Scarcity And Water Trade: An Analysis Of The Determinants Of Virtual Water Flows To The GCC Countries
}

$\underline{10.5339 / \mathrm{qfarc} .2014 . \mathrm{SSPP} 0126}$

Assem Abouhatab, Phd

Corresponding AUTHOR :

assem.abouhatab@gmail.com;assem.abouhatab@slu.se

The Swedish University Of Agricultural Sciences, Uppsala, Sweden

\section{Abstract}

With projected populations of about 633 million in the Arab region in 2050, water resources per capita are expected to drop to a level of about 470 cubic meters in region, compared with a world average of about 4,700 m3 for the same year (Sadik, 2013). Especially, the Gulf Cooperation Council (GCC) countries face the most severe water shortages in the region which represents a serious threat to the region's human security (A1-Zubari, 2008; Dziuban, 2011).

With such diminishing per capita water resources, GCC countries rely on imports to meet the increasing food demand for the growing population, while they import more than 80 percent of their total food consumption (FAO, 2013). A look at the existing literature shows that virtual water, termed by (Allan, 1997), has always been suggested as a means of overcoming water shortage in water scared countries (Hoekstra and Hung 2002; E1-Sadek 2010; Aldaya et al, 2010; Dalin et al. 2012). Few studies however have so far examined the determinants of virtual water flows into the GCC countries. Moreover, previous analyses used high aggregated level of data (developing countries, and the Middle-East region) and in most of cases the GCC countries were neither fully covered nor properly analyzed.

The present paper is original and novel in that it provides a fresh perspective to the debate on the virtual water by focusing on the six GCC countries. To this end, the paper uses a cross-sectional dataset within a gravity model framework to examine the determinants of food imports by the GCC countries from their traditional trading partners while placing special focus on the importance of water scarcity related variables in explaining their food import pattern.

Results show that coefficients on the traditional determinants of trade including per capita GDP, population and distance are in line with the gravity model hypotheses. Most importantly, water-scarcity related variables have the expected signs and plausible. Specially, a negative and statistically significant relationship exists between the percentage of water allocated to agricultural purposes and food imports by GCC countries. Moreover, the results indicate that the high the pressure on the renewable water resources, the more the food imports of the GCC countries expand. While water shortage is expected to increase during the coming decades, food imports in the GCC countries, therefore, would also continue to increase. The study concludes that GCC countries should respond proactively by negotiating food and agricultural trade agreements with potential food suppliers of food and to utilize overseas agro-food investments in order to ensure privileged access to food production and to cope with the likely negative impacts addressed by the increased water scarcity. 